\title{
Rhus verniciflua Stokes extract induces inhibition of cell growth and apoptosis in human chronic myelogenous leukemia $\mathrm{K562}$ cells
}

\author{
KYUNG-WOOK LEE, EUN-SIK UM, BO-BAE JUNG, EUN-SOL CHOI, EUN-YOUNG KIM, \\ SEUNGBO LEE, EUNGYEONG JANG, JANG-HOON LEE and YOUNGCHUL KIM
}

Department of Clinical Korean Medicine, Graduate School, Kyung Hee University, Seoul 02447, Republic of Korea

Received May 16, 2017; Accepted December 15, 2017

DOI: $10.3892 / o r .2018 .6179$

\begin{abstract}
Rhus verniciflua Stokes has been widely used as a traditional medicinal plant with a variety of pharmacological activities. We investigated the mechanisms involved in mediating the effects of Rhus verniciflua Strokes (R. verniciflua) extract in human chronic myelogenous leukemia K562 cells, including caspase-dependent apoptotic pathways related to cell-cycle arrest, as well as the inhibition of nuclear factor NF- $\kappa \mathrm{B}$ activation and upregulation of the mitogen-activated protein kinase (MAPK) signaling pathway. $R$. verniciflua extract suppressed the abnormal cellular proliferation of K562 cells in a dose- and time-dependent manner and increased the quantitative proportions of cells involved in the early and late process of apoptosis. Furthermore, R. verniciflua extract significantly mediated the mRNA levels of pro-apoptotic and anti-apoptotic regulators, such as Bcl-2, Bax, Mcl-1 and survivin in apoptotic cells. Particularly, the treatment of K562 cells with $R$. verniciflua extract augmented the caspase-3 activity and increased the expression of caspase- 3 protein, while co-treatment with $R$. verniciflua extract and the permeant pan-caspase inhibitor Z-VAD-FMK and caspase-3 inhibitor Z-DEVD-FMK inversely enhanced the proliferation of K562 cells. The extract of $R$. verniciflua inhibited the activation of NF- $\mathrm{KB}$ and the phosphorylation of ERK. Collectively, these results indicated that the extract of $R$. verniciflua inhibited the proliferation of human chronic myelogenous leukemia K562 cells by activating the apoptotic process via caspase- 3 overexpression and the regulation of the NF- $\mathrm{\kappa B}$ and MAPK signaling.
\end{abstract}

\section{Introduction}

Rhus verniciflua Stokes (R. verniciflua) has long been used as a traditional herbal medicine, mainly in East Asia, including

Correspondence to: Dr Youngchul Kim, Department of Clinical Korean Medicine, Graduate School, Kyung Hee University, 23 Kyungheedae-ro, Dongdaemun-gu, Seoul 02447, Republic of Korea

E-mail: yckim@khmc.or.kr

Key words: Rhus verniciflua Stokes, K562 cells, apoptosis, caspase, $\mathrm{NF}-\kappa \mathrm{B}, \mathrm{MAPK}$
South Korea, Japan and China. R. verniciflua Stokes is a medicinal plant used for the treatment of gastrointestinal diseases as well as for relieving symptoms possibly caused by cancer since the 15th century in the East Asian region (1). Previous research has revealed that the extract of $R$. verniciflua has various therapeutic effects, encompassing antioxidant, anti-proliferative, anti-inflammatory and antitumor activities (2-7). Additionally, increasing evidence from experimental studies indicates that the $R$. verniciflua extract decreases oxidative stress and prevents tumor progression, although the molecular mechanisms of these pharmacological effects remain to be determined. According to a recent study of an ethanol extract of R. verniciflua, it efficiently inhibited human lymphoma cell growth, which was evaluated by confirming the apoptotic changes based on increased nuclear fragmentation, the suppressed fluorescence intensity of nuclei stained with propidium iodide and the obvious DNA fragments visualized through the DNA laddering in human lymphoma cells (8).

Apoptosis is a form of programmed cellular death characterized by its abnormal morphological features, including cellular nuclear shrinkage, nuclear fragmentation, cytoplasmic blebbing, chromatin condensation and caspase activation $(9,10)$. Two pathways regulate the apoptotic process: the extrinsic pathway involving the activation of death receptors and the intrinsic or mitochondrial pathway. The anti-apoptotic Bcl-2 family consists of apoptotic mediators that play important roles in the process of programmed cell death. This Bcl-2 family of proteins includes several pro-apoptotic and anti-apoptotic molecules, such as Bax and Bcl-2, which regulate the cellular commitment to apoptosis (11).

The activation of nuclear factor- $\mathrm{\kappa B}(\mathrm{NF}-\kappa \mathrm{B})$ plays a pivotal role in regulating the pathological changes during tumor progression from cellular proliferation to the invasion to other organs. The suppression of NF- $\mathrm{KB}$ transcription factor activation is involved in inhibiting tumor cell growth by inducing apoptosis. NF- $\kappa \mathrm{B}$ and extracellular signaling-regulated kinase (ERK) have long been regarded as the main signaling pathways contributing to several aspects of tumorigenesis, such as cell proliferation and cell death $(12,13)$. Numerous antitumor drugs are known to trigger cell death by inducing apoptosis. However, the pharmacological effects of the $R$. verniciflua extract in inhibiting cell growth via the induction of the apoptotic process in human chronic myelogenous leukemia K562 cells remain unclear. 
In the present study, we examined the mechanism by which the effects of $R$. verniciflua activity in human chronic myelogenous leukemia K562 cells are mediated, including the induction of apoptosis via the caspase-dependent apoptotic effects, as well as the suppression of the expression of the $\mathrm{NF}-\kappa \mathrm{B}$ transcription factor and the activation of the mitogenactivated protein kinase (MAPK) pathway.

\section{Materials and methods}

Extraction of $R$. verniciflua. $R$. verniciflua $(14,15)$ grown in Yeosu (Korea) was purchased from Kyung Hee Pharmaceuticals (Wonju, Korea). Firstly, $1 \mathrm{~kg}$ of $R$. verniciflua was roasted at $180^{\circ} \mathrm{C}$ for $1 \mathrm{~h}$, and then extracted twice with sterile distilled water for $3 \mathrm{~h}$. The supernatant was evaporated and freeze-dried and the extract was obtained as a $43 \mathrm{~g}$ powder (yield, 4.3\%). A constituent analysis using highperformance liquid chromatography (HPLC) revealed that fisetin is one of the major components of the $R$. verniciflua extract (Fig. 1).

Cell culture. The human chronic myelogenous leukemia K562 cell line was purchased from the American Type Culture Collection (ATCC, Manassas, VA, USA). The cells were cultured in RPMI-1640 medium (Gibco; Thermo Fisher Scientific, Grand Island, NY, USA) containing $10 \%$ fetal bovine serum (FBS), $100 \mathrm{U} / \mathrm{ml}$ penicillin and $100 \mu \mathrm{g} / \mathrm{ml}$ streptomycin. The cells were incubated at $37^{\circ} \mathrm{C}$ under a humidified atmosphere of $5 \% \mathrm{CO}_{2}$ and $95 \%$ air.

Cell viability. CellTiter $96 \mathrm{AQ}_{\text {ueous }}$ One Solution (Promega, Madison, WI, USA) was used to assess the intensity of the cellular proliferation. The cells were seeded at a density of $1 \times 10^{4}$ cells/well in 96-well plates and cultivated in different concentrations of $R$. verniciflua extract at $37^{\circ} \mathrm{C}$ for 24,48 and $72 \mathrm{~h}$. A colorimetric assay with PMS/MTS solution determined the cell viability. The absorbance value was determined at $490 \mathrm{~nm}$, with reference subtraction at $650 \mathrm{~nm}$.

Flow cytometry. The cells were incubated under treatment with 100,200 and $300 \mu \mathrm{g} / \mathrm{ml}$ of $R$. verniciflua extract for 24 , 48 and $72 \mathrm{~h}$. After incubation, the cells were harvested and then washed with phosphate-buffered saline (PBS). Apoptosis was detected by the FITC Annexin V apoptosis detection kit (BD Biosciences, San Diego, CA, USA). The cells were incubated in $5 \mu \mathrm{l}$ FITC-conjugated Annexin $\mathrm{V}$ and $5 \mu \mathrm{l}$ propidium iodide (PI) with $100 \mu 1$ binding solution for $15 \mathrm{~min}$ at room temperature in the dark. Annexin V-FITC and PI fluorescence were determined by flow cytometry. Apoptosis was assessed with a FACSCalibur device using CellQuest software (Becton Dickinson and Company, Franklin Lakes, NJ, USA).

Apoptosis assay. To detect apoptosis in K562 cells, apoptotic cells were quantitatively analyzed using a cell death detection ELISAplus kit (Roche Molecular Biochemicals, Mannheim, Germany). The cells $\left(1 \times 10^{4}\right)$ were incubated with 100,200 and $300 \mu \mathrm{g} / \mathrm{ml} \mathrm{R}$. verniciflua extract for 24,48 and $72 \mathrm{~h}$. Subsequently the cells were lysed with $200 \mu l$ lysis buffer. Cell lysates were assayed to detect DNA fragments using the cell death ELISAplus kit according to the manufacturer's instruc- tions. DNA fragmentation was estimated at $405 \mathrm{~nm}$ relative to the untreated control level. A caspase colorimetric assay kit (R\&D Systems, Minneapolis, MN, USA) was used to assess the enzymatic changes of caspase proteases. The K562 cells were treated with 100,200 and $300 \mu \mathrm{g} / \mathrm{ml}$ of $R$. verniciflua extract for 24, 48 and $72 \mathrm{~h}$. The cells were harvested and the cell pellets obtained were lysed with $50 \mu 1$ lysis buffer on ice for $10 \mathrm{~min}$. The concentration of protein in the supernatant (cytosolic extract) was assessed using a BCA protein assay kit (Thermo Fisher Scientific, Rockford, IL, USA). Caspase-3-like protease activity was determined using methods for identifying the proteolytic cleavage of substrates, including DEVD-pNA (caspase-3 substrate). These colorimetric substrates were dissolved with an assay buffer. After incubation with the solubilized substrates at $37^{\circ} \mathrm{C}$ for $1 \mathrm{~h}$ in the dark, the intensity of color production in the lysates was assessed with a microplate reader capable of detecting the absorbance at a wavelength of $405 \mathrm{~nm}$ and we compared the caspase-3 activity with the level of the control. To assess the effect of co-treatment with a caspase inhibitor on cell viability, K562 cells $\left(1 \times 10^{4}\right.$ cells $)$ were pretreated with a pan-caspase inhibitor, Z-VAD-FMK, or a caspase-3-specific inhibitor, Z-DEVD-FMK (R\&D Systems) for $2 \mathrm{~h}$. Subsequently, we treated the K562 cells with $300 \mu \mathrm{g} / \mathrm{ml}$ $R$. verniciflua extract. Following the caspase inhibitor and the $R$. verniciflua extract treatments, the PMS and MTS reagents were added to the cells. A colorimetric assay determined the absorbance of the colored formazan product at $490 \mathrm{~nm}$ with background subtraction at $650 \mathrm{~nm}$.

RNA extraction and real-time PCR procedures. Total RNA was extracted and purified from cultured cells using an RNeasy Mini kit according to the manufacturer's instructions (Qiagen, Hilden, Germany). First-strand cDNA was then synthesized from $1 \mu \mathrm{g}$ of RNA template using a reverse transcriptase system (Promega). Random hexamers primed the reverse transcription reaction and the primer sequences and product sizes were as follows: Bcl-2 (5'-GATTGATGGGATC GTTGCCTTA-3', 5'-CCTTGGCATGAGATGCAGGA-3'; 200 bp), Bax (5'-GGATGCGTCCACCAAGAAG-3', 5'-GCCT TGAGCACCAGTTTGC-3'; 216 bp), Mcl-1 (5'-CTCATTT CTTTTGGTGCCTTT-3', 5'-CCAGTCCCGTTTTGTCCT TAC-3'; 117 bp), survivin (5'-GGCCCAGTGTTTCTTCTG CTT-3', 5'-GCAACCGGACGAATGCTTT-3'; 91 bp), $\beta$-actin (5'-GCGAGAAGATGACCCAGATC-3', 5'-GGATAGCAC AGCCTGGATAG-3'; 77 bp). Real-time PCR was performed on a StepOnePlus Real-Time PCR system (Applied Biosystems, Foster, CA, USA) with the Power SYBR-Green PCR Master Mix (Applied Biosystems). We performed the PCR with $1 \mu \mathrm{l}$ cDNA in $20 \mu 1$ reaction mixtures that consisted of $10 \mu 1$ Power SYBR-Green PCR Master Mix, $2 \mu \mathrm{l}$ primers and $7 \mu \mathrm{l}$ PCR water. The amplifying reactions were processed with an initial denaturing step of the target DNA at $95^{\circ} \mathrm{C}$ for $10 \mathrm{~min}$, followed by 40 cycles of $95^{\circ} \mathrm{C}$ for $15 \mathrm{sec}$ and $60^{\circ} \mathrm{C}$ for $1 \mathrm{~min}$. The formula $2^{\text {-(target gene - } \beta \text {-actin) }}$ was used to calculate the crossing point of target genes with $\beta$-actin and the relative expression amounts were quantified.

Immunoblot analysis. K562 cells were harvested and washed with cold PBS to remove the medium, and then lysed in lysis buffer containing $1 \mathrm{mM}$ PMSF (Cell Signaling Technology, 
A<smiles>O=c1c(O)c(-c2ccc(O)c(O)c2)oc2cc(O)ccc12</smiles>

B

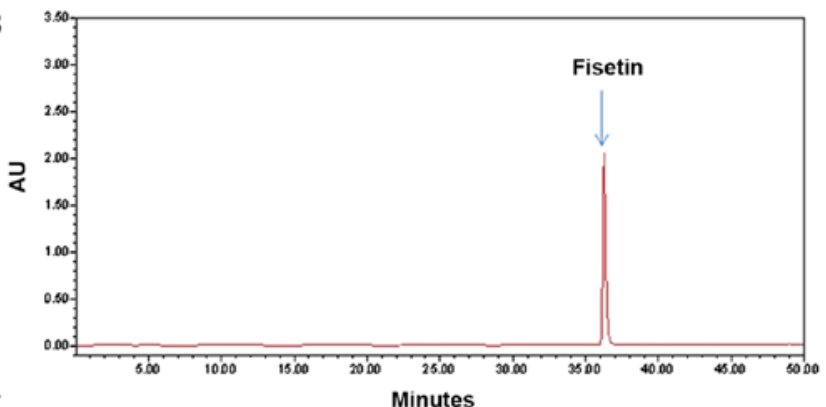

C

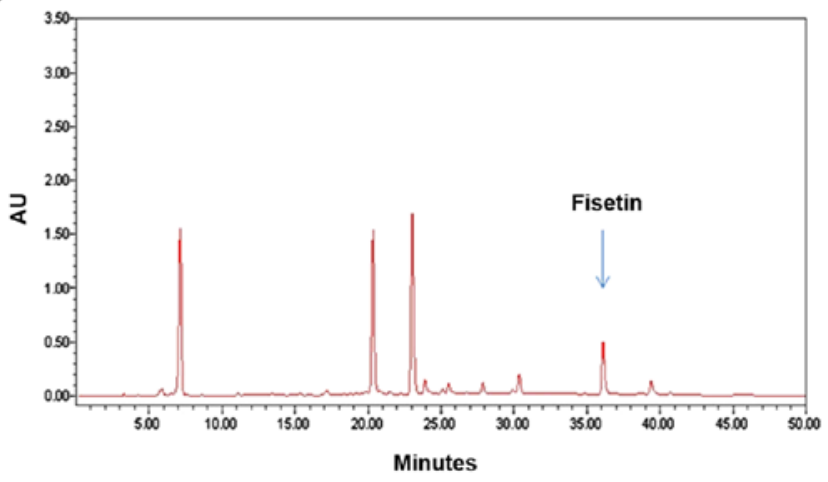

Figure 1. Fisetin chemical structure and high-performance liquid chromatographic profile. (A) Chemical structure of fisetin. (B) Fisetin standard. (C) Water extract of roasted $R$. verniciflua Stokes.

Boston, MA, USA). The concentration of protein contained in the incubated cells was assessed using a BCA protein assay, according to the manufacturer's instructions. The protein sample $(30 \mu \mathrm{g})$ was separated by $12 \%$ SDS-PAGE electrophoresis and transferred onto nitrocellulose membranes. The membranes were rewetted and blocked with 5\% blocking buffer for $1 \mathrm{~h}$ at room temperature, and then incubated overnight with human antibodies against NF- $\kappa \mathrm{B}$ p65 (cat. no. 8242), phosphorylated (p-)NF- $\mathrm{kB}$ p65 (cat. no. 3031), p38 MAPK (cat. no. 9228), p-p38 MAPK (cat. no. 9215), MEK (cat. no. 4694), p-MEK (cat. no. 9154), ERK (cat. no. 4696) and p-ERK1/2 (cat. no. 4376; all from Cell Signaling Technology) and $\beta$-actin (cat. no. A5441; Sigma-Aldrich Co.) diluted 1:1,000 with Tris-buffered saline containing $0.05 \%$ Tween-20 (TBS-T). After $1 \mathrm{~h}$ washing with TBS-T solution, the membranes were incubated with horseradish peroxidaseconjugated secondary antibodies (rabbit; cat. no. 7074 mouse; cat. no. 7076; both from Cell Signaling Technology) diluted 1:2,500 in TBS-T solution for $1 \mathrm{~h}$ at room temperature. These incubated membranes were subsequently washed with TBS-T solution for $1 \mathrm{~h}$ and the proteins were determined using an Amersham ECL Prime reagent kit (GE Healthcare Life Sciences, Little Chalfont, UK). The protein expression from cultured cells was detected using a Davinch-Chemi Chemiluminescence Imaging system (Davinch-K Co., Ltd., Seoul, Korea).

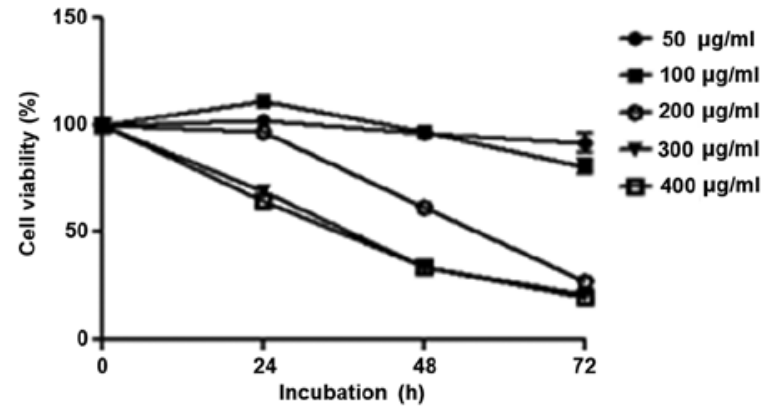

Figure 2. Effects of $R$. verniciflua extract on K562 cell growth. The cells were treated with various concentrations of $R$. verniciflua extract $(0-400 \mu \mathrm{g} / \mathrm{ml})$ for 24, 48 and $72 \mathrm{~h}$. Cell viability was assessed with the PMS/MTS assay. The control group was assigned a value of $100 \%$. Data are expressed as the means \pm SD of triplicate samples.

Statistical analysis. Values are expressed as the mean \pm SD. Student's t-test was used to evaluate differences between the control group and the $R$. verniciflua extract-treated groups. The degree of inhibition of apoptosis was determined by the differences between the $R$. verniciflua extract-treated sample and the samples treated with a combination of caspase inhibitor and $R$. verniciflua extract. The data were analyzed statistically using GraphPad Prism 5.0 (GraphPad Software, San Diego, CA, USA). $\mathrm{p}<0.05$ and $\mathrm{p}<0.01$ were considered to indicate statistically significant differences.

\section{Results}

R. verniciflua extract inhibits cell proliferation. K562 cells were treated with increasing concentrations of $R$. verniciflua extract $(0-500 \mu \mathrm{g} / \mathrm{ml})$ for 24,48 and $72 \mathrm{~h}$. The effects of $R$. verniciflua extract on K562 cellular proliferation were evaluated using a PMS/MTS solution. In the 200 and $300 \mu \mathrm{g} / \mathrm{ml}$ treated groups, the $\mathrm{IC}_{50}$ values were 211 and $457 \mu \mathrm{g} / \mathrm{ml}$ respectively when calculated by the cell viabilities of the three time-points. The morphologies of the cells were not changed with those concentrations. $R$. verniciflua extract suppressed cell proliferation in a dose- and time-dependent manner in K562 cells (Fig. 2).

$R$. verniciflua extract induces cell cycle progression. The K562 cells were treated with increasing concentrations of 100 , 200 and $300 \mu \mathrm{g} / \mathrm{ml}$ R. verniciflua extract for 24,48 and $72 \mathrm{~h}$. To determine whether the $R$. verniciflua extract induced cellcycle arrest, the apoptotic cell distribution was assessed by flow cytometry. The R. verniciflua extract increased the number of apoptotic cells in the early and late stages in a dose- and timedependent manner when compared with the controls (Fig. 3).

R. verniciflua extract induces cell apoptosis and caspase activation. The K562 cells were treated with 100, 200 and $300 \mu \mathrm{g} / \mathrm{ml}$ R. verniciflua extract for 24,48 and $72 \mathrm{~h}$ and we used a cell death detection ELISA assay to identify apoptotic cells (Fig. 4A). The numbers of apoptotic cells were significantly increased in a dose-and time-dependent manner under the treatment of $R$. verniciflua extract. Caspase-3 activity was assayed using a colorimetric ELISA and the level of caspase-3 protein was assessed by immunoblotting. Caspase-3 activity 

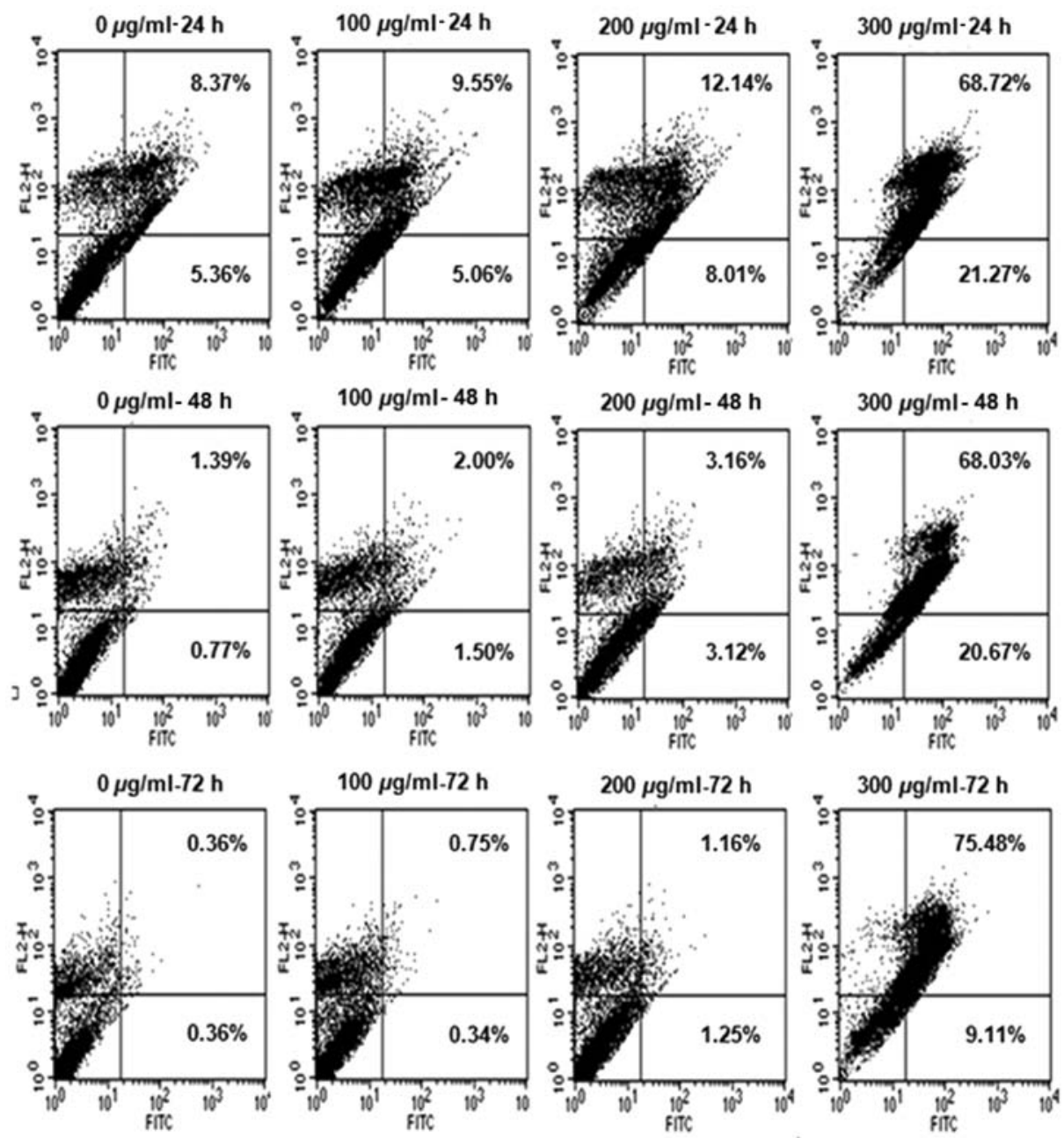

Figure 3. Effects of $R$. verniciflua extract on early and late apoptosis fractions in K562 cells. The cells were treated with $R$. verniciflua extract (0, 100,200 and $300 \mu \mathrm{g} / \mathrm{ml}$ ) for 24,48 and $72 \mathrm{~h}$. Apoptosis was assessed by flow cytometry with Annexin V-FITC and propidium iodide (PI) fluorescence. The data are the means \pm SD of three independent samples. ${ }^{*} \mathrm{p}<0.05$ and ${ }^{* *} \mathrm{p}<0.01$ compared with the control.

and protein expression were enhanced in a dose- and timedependent manner following treatment with $R$. verniciflua extract (Fig. 4B and C). To determine whether the caspase-3 activation was associated with the $R$. verniciflua extractinduced apoptosis, K562 cell proliferation was detected by a PMS/MTS solution with $R$. verniciflua extract treatment. Pretreatment with the pan-caspase inhibitor Z-VAD-FMK and the caspase-3 inhibitor Z-DEVD-FMK on K562 cells increased $R$. verniciflua extract-induced cell proliferation (Fig. 4D).

$R$. verniciflua extract regulates $m R N A$ transcription. The K562 cells were treated with 100, 200 and $300 \mu \mathrm{g} / \mathrm{ml}$ of $R$. verniciflua extract for 24,48 and $72 \mathrm{~h}$. Subsequently, the mRNA levels of the apoptotic genes Bcl-2, Bax, Mcl-1 and survivin were assessed using real-time PCR. The mRNA levels of Bcl-2, Mcl-1 and survivin were decreased in a dose- and time-dependent manner, whereas the Bax level was increased (Fig. 5).

$R$. verniciflua extract inactivates $N F-\kappa B$ p65 and the activity of MAPK signaling. The K562 cells were treated with 100 , 200 and $300 \mu \mathrm{g} / \mathrm{ml}$ of $R$. verniciflua extract for 24,48 and
$72 \mathrm{~h}$. The expression of NF- $\mathrm{NB}$ and MAPK proteins were analyzed by immunoblotting. The levels of the activation and phosphorylation of important proteins in the K562 cells were inhibited significantly. The levels of NF- $\mathrm{B}$ p65 and of p38 MAPK, MEK and ERK1/2 phosphorylation were markedly suppressed (Fig. 6A and B).

\section{Discussion}

R. verniciflua Stokes has long been used as a therapeutic medicinal herb in Asian countries. To investigate the potent pharmacological effect of $R$. verniciflua extract against K562 leukemia cells, we identified the effect of $R$. verniciflua extract on the viability of the K562 cells. $R$. verniciflua extract inhibited K562 cell proliferation, as previously reported (16). Experimental results from the present study indicated that $R$. verniciflua extract not only blocked K562 cells in early and late stages of apoptosis but also increased the apoptotic cell numbers. A recent study reported a quantitative decrease in the number of A431 cells in the G1 phase and cellular arrest in the sub-G0/G1 phase after treatment with triptolide (17).

Caspases are central components of the mechanism responsible for apoptosis (18). To determine the molecular mechanism 
A

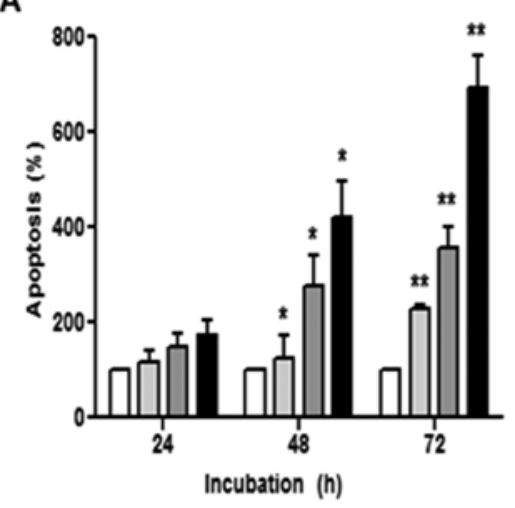

C
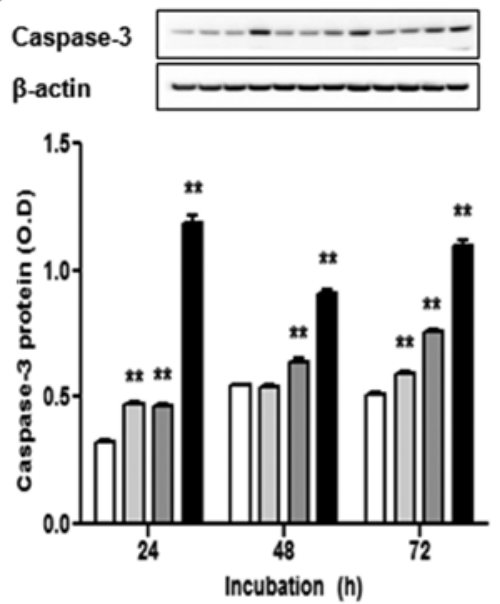

B

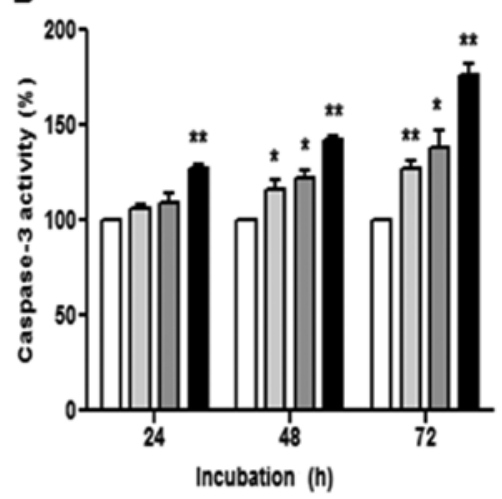

D

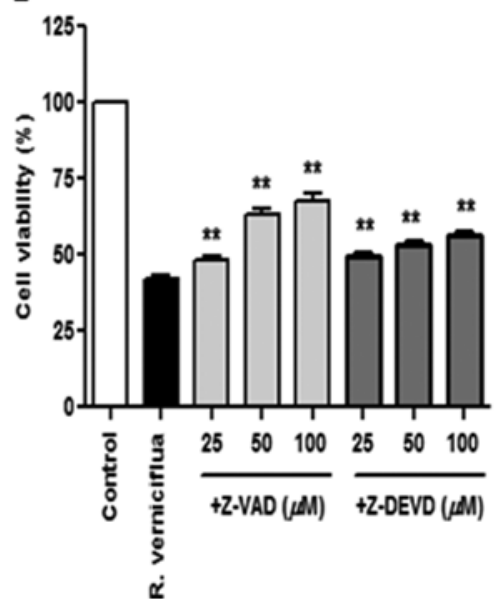

Figure 4. Effects of $R$. verniciflua extract on the induction of apoptosis in K562 cells. The cells were cultured with various concentrations of $R$. verniciflua extract $(0,100,200$ and $300 \mu \mathrm{g} / \mathrm{ml})$ for 24, 48 and $72 \mathrm{~h}$. (A) A cell death detection ELISA was used to quantify apoptotic cells. Effects of $R$. verniciflua extract on caspase-3 activity and protein expression in K562 cells. (B) Caspase-3 activity was assessed with a caspase-3 colorimetric assay. (C) Levels of caspase-3 protein were examined using immunoblotting. Values are the means \pm SDs of three independent experiments. ${ }^{*} \mathrm{p}<0.05$ and ${ }^{* *} \mathrm{p}<0.01$ vs. the control. (D) K562 cells were pretreated with Z-VAD (pan-caspase inhibitor) and Z-DEVD (caspase-3-specific inhibitor) for $2 \mathrm{~h}$ and were then incubated with $300 \mu \mathrm{g} / \mathrm{ml}$ $R$. verniciflua extract for $72 \mathrm{~h}$. The cell proliferation was determined using a PMS/MTS assay. Values are the means \pm SD of three independent experiments. ${ }^{*} \mathrm{p}<0.05$ and ${ }^{* *} \mathrm{p}<0.01, R$. verniciflua extract-treated cells vs. $R$. verniciflua extract and caspase inhibitor-treated cells.
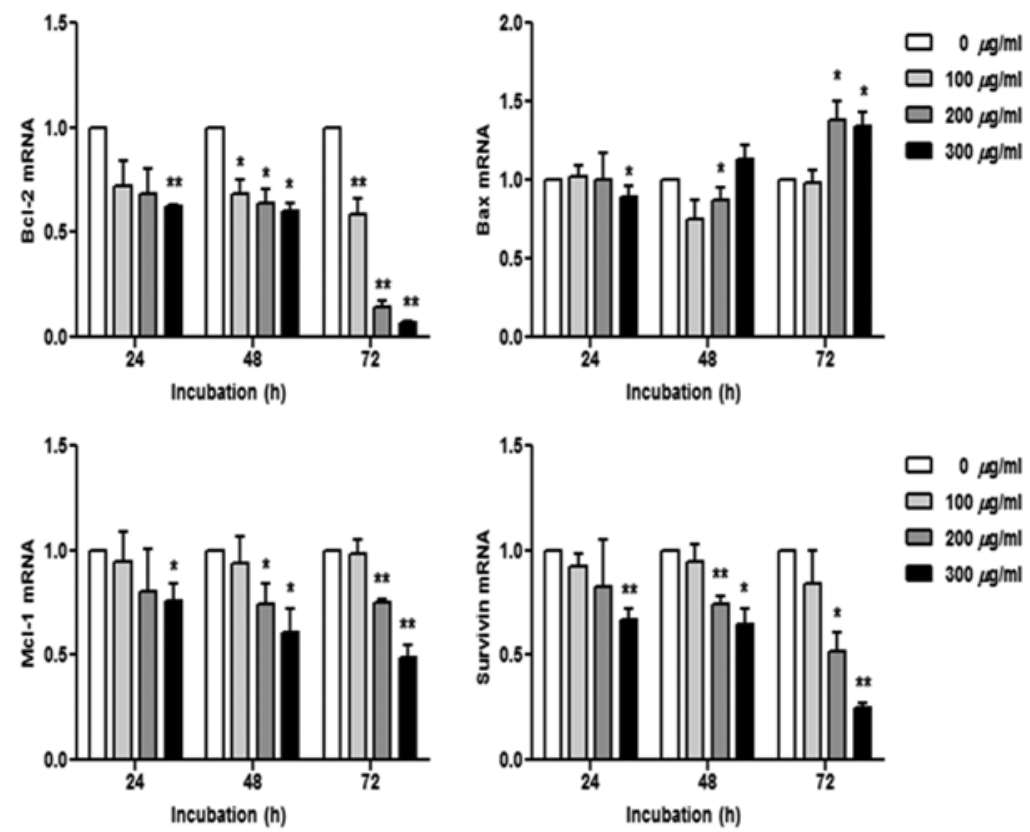

Figure 5. Effects of $R$. verniciflua extract on mRNA expression in K562 cells. The cells were treated with $R$. verniciflua extract $(0,100,200 \mathrm{and} 300 \mu \mathrm{g} / \mathrm{ml})$ for 24,48 and $72 \mathrm{~h}$. The mRNA expression was detected by real-time PCR. The crossing points of Bcl-2, Bax, Mcl-1 and survivin with $\beta$-actin were entered into the formula $2^{- \text {-target gene- }-\beta \text {-actin) }}$ and relative amounts were quantified. Values are the means \pm SD of three independent experiments. ${ }^{*} p<0.05$ and ${ }^{* *}$ p $<0.01$ vs. the control. 
A

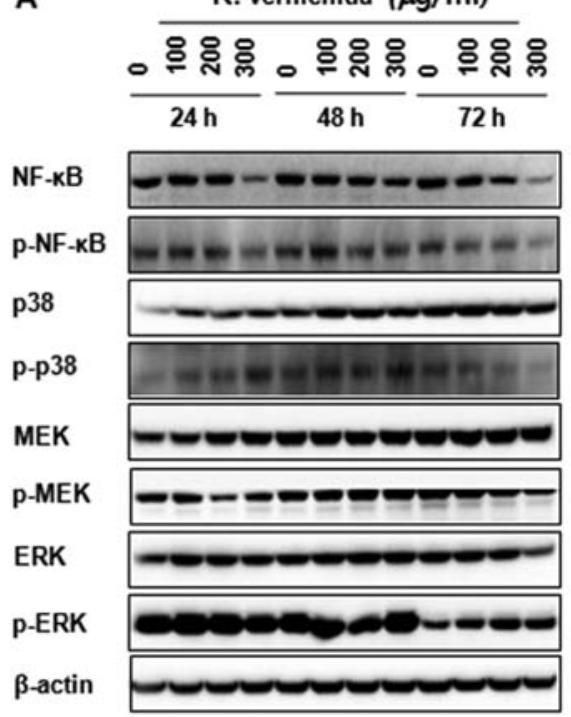

B
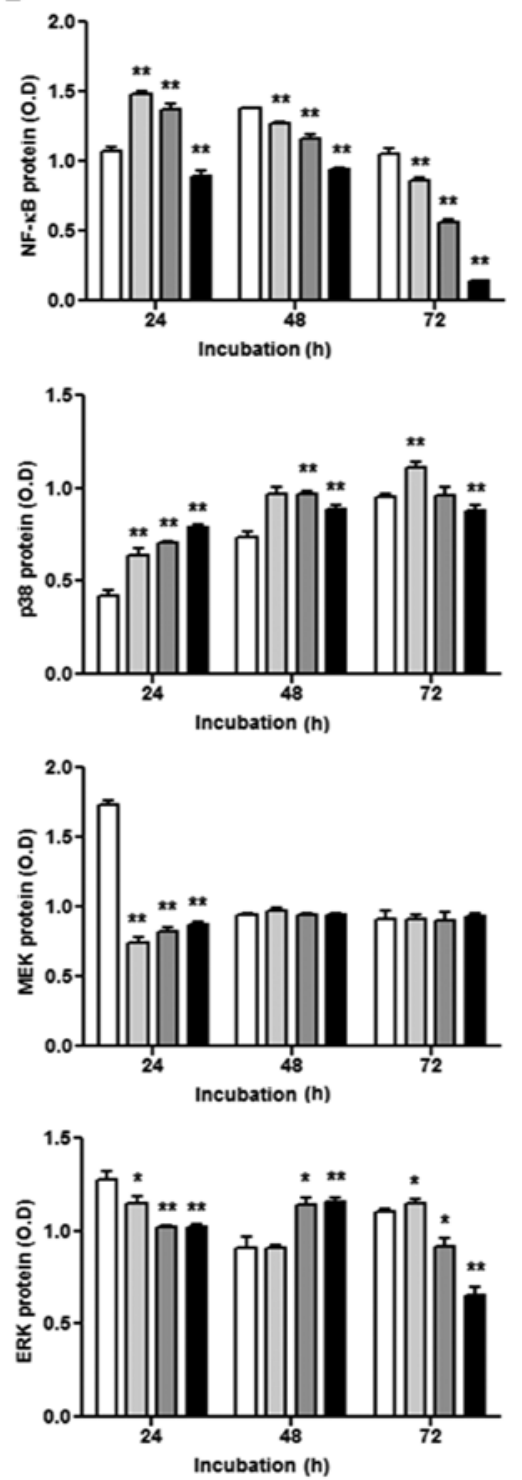

of apoptosis in K562 cells, we revealed that treatment with $R$. verniciflua extract increased intracellular caspase-3 activity and enhanced the levels of caspase- 3 and cleaved caspase- 3 protein. This result was confirmed by co-treatment using a pan-caspase inhibitor and caspase-3-specific inhibitor, which led to an inverse in $R$. verniciflua extract-mediated cell proliferation. These results indicated that $R$. verniciflua extract-induced apoptosis pathway was associated with caspase activation in K562 cells. We then found that the K562 cells exhibited reduced mRNA expression levels of Bcl-2, Mcl-1 and survivin with $R$. verniciflua extract treatment, whereas the Bax level was increased. These results indicated that $R$. verniciflua extract induced apoptosis through the regulation of anti- and pro-apoptotic genes and the activation of caspase-3. Tubeimoside-1 increased the apoptotic activities of caspase-3, -8 and -9 , whereas a caspase-3-specific inhibitor significantly inhibited tubeimoside-1-induced apoptosis in
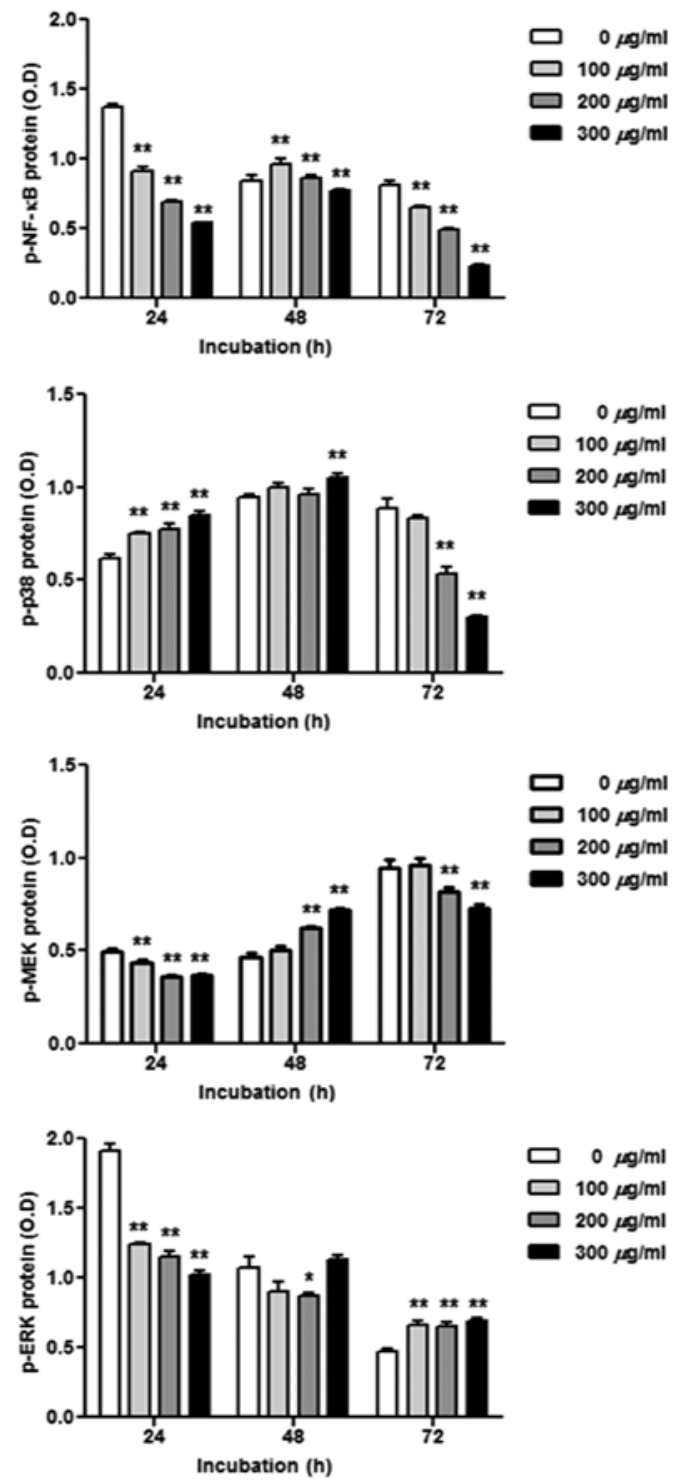

Figure 6. Effects of $R$. verniciflua extract on the NF-кB and MAPK protein expression in K562 cells. The cells were treated with $R$. verniciflua extract $(0,100$, 200 and $300 \mu \mathrm{g} / \mathrm{ml}$ ) for 24,48 and $72 \mathrm{~h}$ and the protein expression was assessed by immunoblotting. (A) The cells were lysed and $30 \mu \mathrm{g}$ of soluble protein mixture was separated by electrophoresis through an SDS-PAGE gel. (B) Densitometric analyses of proteins are presented as the relative ratios of NF- $\kappa$ B, $\mathrm{p} 38$ MAPK, MEK, ERK and $\beta$-actin. Values are the means \pm SDs of three independent experiments. ${ }^{*} \mathrm{p}<0.05$ and ${ }^{* *}$ p $<0.01$ vs. the control. 
HepG2 cells. Tubeimoside-1-induced apoptosis also decreased Bcl-2 and increased Bak, with no change in Bax levels (19).

$\mathrm{NF}-\kappa \mathrm{B}$ is a key regulator consisting of a variety of transcription factors related to both pro- and anti-apoptotic processes. $\mathrm{Bcl}-2$ and $\mathrm{Bcl}-\mathrm{X}_{\mathrm{L}}$ are anti-apoptotic molecules belonging to the $\mathrm{Bcl}-2$ family and their expression level is regulated by the activation of the NF- $\kappa \mathrm{B}(20,21)$. NF- $\kappa \mathrm{B}$ is a critical transcription factor that plays a pivotal role in the expression of apoptosisrelated proteins (22). In the present study, $R$. verniciflua extract inhibited the $\mathrm{NF}-\kappa \mathrm{B}$ activity. Therefore, blocking of the $\mathrm{NF}-\kappa \mathrm{B}$ signaling pathway may be effective at inducing apoptosis in K562 cells. Triptolide induced apoptosis of human anaplastic thyroid carcinoma cells by suppressing the NF- $\kappa \mathrm{B}$ expression. It also downregulated $\mathrm{Bcl}-2$ and $\mathrm{Bcl}-\mathrm{X}_{\mathrm{L}}$, which were transcriptionally mediated by $\mathrm{NF}-\kappa \mathrm{B}$-dependent and $\mathrm{p} 53$-independent mechanisms (23). Our results indicated that $R$. verniciflua extract induced apoptosis by the downstream inhibition of the NF- $\kappa \mathrm{B}$ signaling and the expression of the gene encoding Bcl-2.

MAPK pathway is an important regulator of cell death, proliferation, differentiation and autophagy $(24,25)$. We demonstrated that $R$. verniciflua extract inhibited MAPK signaling in the K562 cells. Gleditsia sinensis thorn induced p38 MAPK, ERK1/2 and JNK phosphorylation in human colon cancer cells (26). Guibi-tang (GBT) treatment upregulated the expression of p38, ERK and JNK, which were retained during apoptosis in the A431 cells (27). Ponicin inhibited cell growth by arresting G1-cell cycle and inducing apoptosis in HT29 cells. The Akt and MEK signaling pathway were also blocked by ponicin, whereas the p38 MAPK signaling was activated (28). In the present study, our results revealed that $R$. verniciflua extract inhibited K562 cell proliferation by inducing apoptosis and suppressing the MAPK signaling pathways.

In conclusion, in the present study, we demonstrated that $R$. verniciflua extract induced apoptosis, contributing to the inhibition of $\mathrm{K} 562$ cell proliferation, which is partly mediated by caspase activation, inhibition of the NF- $\kappa \mathrm{B}$ activity and suppression of MAPK signaling. These results indicated the need for further research on the in vivo effect of the $R$. verniciflua extract.

\section{References}

1. Choi W, Jung H, Kim K, Lee S, Yoon S, Park J, Kim S, Cheon S Eo $\mathrm{W}$ and Lee S: Rhus verniciflua stokes against advanced cancer: A perspective from the Korean Integrative Cancer Center. J Biomed Biotechnol 2012: 874276, 2012.

2. Lim KT, Hu C and Kitts DD: Antioxidant activity of a Rhus verniciflua Stokes ethanol extract. Food Chem Toxicol 39: 229-237, 2001.

3. Kitts DD and Lim KT: Antitumorigenic and cytotoxic properties of an ethanol extract derived from Rhus verniciflua Stokes (RVS). J Toxicol Environ Health A 64: 357-371, 2001.

4. Lee JD, Huh JE, Jeon G, Yang HR, Woo HS, Choi DY and Park DS: Flavonol-rich RVHxR from Rhus verniciflua Stokes and its major compound fisetin inhibits inflammation-related cytokines and angiogenic factor in rheumatoid arthritic fibroblastlike synovial cells and in vivo models. Int Immunopharmacol 9: 268-276, 2009

5. Lee JC, Lim KT and Jang YS: Identification of Rhus verniciflua Stokes compounds that exhibit free radical scavenging and antiapoptotic properties. Biochim Biophys Acta 1570: 181-191, 2002.
6. Lee JC, Lee KY, Kim J, Na CS, Jung NC, Chung GH and Jang YS: Extract from Rhus verniciflua Stokes is capable of inhibiting the growth of human lymphoma cells. Food Chem Toxicol 42: $1383-1388,2004$

7. Jang HS, Kook SH, Son YO, Kim JG, Jeon YM, Jang YS Choi KC, Kim J, Han SK, Lee KY, et al: Flavonoids purified from Rhus verniciflua Stokes actively inhibit cell growth and induce apoptosis in human osteosarcoma cells. Biochim Biophys Acta 1726: 309-316, 2005

8. Lee JC, Kim J and Jang YS: Ethanol-eluted extract of Rhus verniciflua stokes inhibits cell growth and induces apoptosis in human lymphoma cells. J Biochem Mol Biol 36: 337-343, 2003

9. Kerr JF, Wyllie AH and Currie AR: Apoptosis: A basic biological phenomenon with wide-ranging implications in tissue kinetics. Br J Cancer 26: 239-257, 1972.

10. Wyllie AH, Kerr JF and Currie AR: Cell death: The significance of apoptosis. Int Rev Cytol 68: 251-306, 1980.

11. Levine B, Sinha S and Kroemer G: Bcl-2 family members: Dual regulators of apoptosis and autophagy. Autophagy 4: 600-606, 2008.

12. Stanciu M, Wang Y, Kentor R, Burke N, Watkins S, Kress G, Reynolds I, Klann E, Angiolieri MR, Johnson JW, et al: Persistent activation of ERK contributes to glutamate-induced oxidative toxicity in a neuronal cell line and primary cortical neuron cultures. J Biol Chem 275: 12200-12206, 2000.

13. Aggarwal BB: Nuclear factor-kappaB: The enemy within. Cancer Cell 6: 203-208, 2004

14. Yun-Yang W, Yu-Min D, Fang-Xing Y, Ying X, Rong-Zhi C and Kennedy JF: Purification and characterization of hydrosoluble components from the sap of Chinese lacquer tree Rhus vernicifera. Int J Biol Macromol 38: 232-240, 2006.

15. Lee SH, Choi WC and Yoon SW: Impact of standardized Rhus verniciflua stokes extract as complementary therapy on metastatic colorectal cancer: A Korean single-center experience. Integr Cancer Ther 8: 148-152, 2009.

16. Choi HS, Seo HS, Kim SR, Choi YK, Jang BH, Shin YC and Ko SG: Anti-inflammatory and anti-proliferative effects of Rhus verniciflua Stokes in RAW264.7 cells. Mol Med Rep 9: 311-315, 2014.

17. Park SW and Kim YI: Triptolide induces apoptosis of PMA-treated THP-1 cells through activation of caspases, inhibition of NF- $\mathrm{KB}$ and activation of MAPKs. Int J Oncol 43: 1169-1175, 2013.

18. Li J and Yuan J: Caspases in apoptosis and beyond. Oncogene 27: 6194-6206, 2008.

19. Yin Y, Chen W, Tang C, Ding H, Jang J, Weng M, Cai Y and Zou G: NF- $\kappa \mathrm{B}$, JNK and $\mathrm{p} 53$ pathways are involved in tubeimoside-1-induced apoptosis in HepG2 cells with oxidative stress and $\mathrm{G}_{2} / \mathrm{M}$ cell cycle arrest. Food Chem Toxicol 49: 3046-3054, 2011.

20. Burlacu A: Regulation of apoptosis by $\mathrm{Bcl}-2$ family proteins. J Cell Mol Med 7: 249-257, 2003.

21. 21. Kuwana $T$ and Newmeyer DD: Bcl-2-family proteins and the role of mitochondria in apoptosis. Curr Opin Cell Biol 15: 691-699, 2003.

22. Reed JC: Apoptosis-targeted therapies for cancer. Cancer Cell 3: 17-22, 2003.

23. Zhu W, Hu H, Qiu P and Yan G: Triptolide induces apoptosis in human anaplastic thyroid carcinoma cells by a p53-independent but NF-kappaB-related mechanism. Oncol Rep 22: 1397-1401, 2009.

24. Rubinfeld $\mathrm{H}$ and Seger R: The ERK cascade: A prototype of MAPK signaling. Mol Biotechnol 31: 151-174, 2005.

25. 25. Cui Q, Tashiro S, Onodera S, Minami M and Ikejima T: Autophagy preceded apoptosis in oridonin-treated human breast cancer MCF-7 cells. Biol Pharm Bull 30: 859-864, 2007.

26. Lee SJ, Park K, Ha SD, Kim WJ and Moon SK: Gleditsia sinensis thorn extract inhibits human colon cancer cells: The role of ERK1/2, G2/M-phase cell cycle arrest and p53 expression. Phytother Res 24: 1870-1876, 2010.

27. Yim NH, Kim A, Liang C, Cho WK and Ma JY: Guibitang, a traditional herbal medicine, induces apoptotic death in A431 cells by regulating the activities of mitogen-activated protein kinases. BMC Complement Altern Med 14: 344, 2014.

28. Du J, Chen C, Sun Y, Zheng L and Wang W: Ponicidin suppresses HT29 cell growth via the induction of G1 cell cycle arrest and apoptosis. Mol Med Rep 12: 5816-5820, 2015. 